\title{
Predictors of Foot Ulcers Among Diabetic Patients at a Tertiary Care Center, Egypt
}

\author{
Yasmine Samir Galal' \\ Walaa Ahmed Khairy (D) \\ Ahmed Ali Taha ${ }^{2}$ \\ Tarek Tawfik Amin' \\ 'Public Health and Community Medicine \\ Department, Faculty of Medicine, Cairo \\ University, Cairo, Egypt; ${ }^{2}$ Vascular \\ Surgery Consultant, National Institute of \\ Diabetes and Endocrinology, Cairo, Egypt
}

Correspondence: Walaa Ahmed Khairy Public Health and Community Medicine Department, Faculty of Medicine, Cairo University, Kasr Alainy Street, Cairo,

II 562, Egypt

Tel +20-I22368208I

Email Walaa.khairy@kasralainy.edu.eg
Background and Purpose: Diabetic foot ulcers (DFUs) markedly contribute to morbidity and mortality of diabetic patients. Hence, this study was conducted to investigate the predictors of foot ulcers among Egyptian diabetic patients.

Methods: A case-control study was conducted among 488 diabetic patients attending the inpatient departments and outpatient clinics at the National Diabetes Institute in Egypt. A pretested data collection sheet was designed to collect and record the following: sociodemographic data, diabetic history and lifestyle characteristics, recorded comorbidities, and the results of foot examination.

Results: Significant positive predictors of DFUs on multivariate logistic regression analysis included presence of three or more comorbidities; two or more diabetic complications; callus; and flatfoot. Significant protective (negative) predictors were management of diabetes by diet, oral hypoglycemic drugs (OHGs), and insulin; and intact vibration sense.

Conclusion: Significant positive predictors of DFUs on multivariate analysis were presence of three or more comorbidities, two or more diabetic complications, callus and flatfoot, while protective predictors were management of diabetes by diet, OHGs, and insulin; and intact vibration sense. Hence, close monitoring should be provided to diabetic patients with comorbidities and complications to reduce the risk of DFUs.

Keywords: diabetic foot ulcers, comorbidities, peripheral vascular disease, foot deformities

\section{Introduction}

Diabetes mellitus (DM) is a major public health problem worldwide and is considered one of the main global health emergencies of the 21 st century. ${ }^{1}$ The prevalence of DM is increasing in both developed and developing countries, recent estimates indicate that there were 463 million adults living with diabetes in 2019 which is projected to increase to 642 million in $2040 .^{2,3}$ In the Middle East and North Africa (MENA) region, the number of patients with diabetes is expected to increase from 34.6 million in 2013 to 67.9 million by $2035 .^{2}$ The International Diabetes Federation (IDF) classified Egypt among the top 10 countries in the world with the highest prevalence of diabetes, where about 9 million adults between 20 and 79 years of age were living with DM in 2019. The number of patients with DM in Egypt has increased rapidly from about 4.5 million in 2007 to 7.5 million in 2013 , and is expected to increase to 13.1 million by 2035 . $^{4}$

There are multiple complications affecting diabetic patients, however, none are more debilitating than those involving the foot. ${ }^{5}$ Diabetic foot ulcers (DFUs) markedly contribute to morbidity of diabetic patients; they prolong hospital stays and account for nearly $20 \%$ of all diabetes-related hospitalizations. ${ }^{6}$ The lifetime risk of developing 
foot ulcers among diabetic patients ranges from 19\% up to $34 \%$, and about $85 \%$ of all diabetic lower limb amputations (DLLA) are preceded by DFUs. ${ }^{7,8}$ Mortality rate following DLLA because of foot ulcers ranges from $24.6 \%$ within 5 years to $45.4 \%$ within 10 years. $^{9}$ Beside morbidity and mortality, DFUs impose a huge socio-economic burden on the patients and their families. ${ }^{10}$ Moreover, they have a significant effect on the patients' quality of life, being a major cause of depression and physical disability. ${ }^{7}$

The pooled global prevalence of DFUs was estimated to be $6.3 \%$ according to a systematic review involving more than 800,000 participants diagnosed with DM worldwide. ${ }^{11}$ Moreover, results of the systematic review revealed a higher prevalence of DFUs in Africa (7.2\%) than in Asia (5.5\%) and Europe (3\%). ${ }^{11}$ According to studies conducted in Egypt, the prevalence of DFUs among diabetic patients ranges from $6.1 \%$ to $29.3 \%$. $^{12,13}$

As per the International Working Group on the Diabetic Foot (IWGDF) guidelines, ${ }^{14}$ DFUs have a complicated etiology, to which several factors contribute including socio-demographic factors like age, gender, residence, and educational status; ${ }^{15-17}$ clinical factors as duration and type of DM, poor glycemic control, increased body mass index (BMI), and foot deformities. ${ }^{17,18}$ Comorbidities including peripheral vascular disease (PVD), retinopathy, nephropathy, and neuropathy are also associated with an increased risk of developing DFUs. ${ }^{11,19}$ In addition, DFUs are also affected by life style factors such as smoking, alcohol intake, exercise, and habits of foot self-care practice. ${ }^{17}$

However, predictors of DFUs vary across different socioeconomic, cultural, and demographic factors. Therefore, investigating these factors worldwide is crucial to provide health care workers and policy makers with the needed information to prevent the devastating impact of DFUs. ${ }^{19}$ In Egypt, few studies have assessed the factors associated with DFUs; ${ }^{12,13}$ hence, this study was conducted to investigate the predictors of DFUs among Egyptian diabetic patients attending the National Diabetes Institute, Cairo, Egypt. The current study provides more in-depth estimate of the research problem in Egypt being conducted in a tertiary care facility like the "National Diabetes Institute" which serves as the most crucial endpoint for all referred diabetic cases from all over Egypt. Additionally, more study variables were investigated in the current work.

\section{Methods}

\section{Study Design, Setting, and Participants}

This case-control study was conducted over 8-months, from the beginning of October 2019 to the end of May 2020, to explore the predictors of foot ulcers among diabetic patients attending the inpatient departments and outpatient clinics of the National Diabetes Institute in Cairo, Egypt. This institute is a tertiary care facility serving at least 20,000 diabetic patients per month for follow up, with inpatients department of 120 beds to manage diabetes complications including surgery.

Inclusion criteria for the study population included patients diagnosed with type II diabetes according to the international standards [fasting blood glucose $\geq 7.0$ $\mathrm{mmol} / \mathrm{l}(126 \mathrm{mg} / \mathrm{dl})$ or 2 hour postprandial plasma glucose $\geq 11.1 \mathrm{mmol} / 1(200 \mathrm{mg} / \mathrm{dl})]^{20}$ and following a diabetic diet or anti-diabetic drug for at least one year, patients $\geq$ 18 years, and those who agreed to participate following personal approach. For the DFU cases, those with recently (incident) diagnosed DFU (one week to three months) were included, they were selected from both inpatient departments and outpatient clinics. A foot ulcer was diagnosed according to the International Consensus on Diabetic foot as full-thickness wound below the ankle in a diabetic patient, regardless of its duration. $^{21}$ Age and sex matched control group was recruited from the outpatient clinics and clinically confirmed free from any foot ulcer. Patients who were critically ill, mentally impaired or pregnant were excluded from the study.

\section{Sample Size}

The sample size was calculated by using the OpenEpi open source ${ }^{22}$ considering two sided confidence interval of $95 \%$ and power of $80 \%$, with proportion of cases exposed to DFU of at least $27 \%$ and controls of $15 \%$, and the least Odds ratio of $2.0^{22-24}$ with a ratio of control to cases of 2, the sample size required for cases was 146 and 302 for controls. An additional 10\% increment was added to compensate for non-response, the final sample size was 160 cases and 332 controls. Selection of cases: all confirmed cases who developed and /or admitted having DFU were approached personally with the defined inclusion criteria. For the controls, a systematic sampling technique was employed for their selection from attendees of the outpatient clinics for follow up, where every 7th patient was selected till reaching the required sample 
size. Controls were selected to match cases using frequency method in relation to sex and \pm 5 years range.

\section{Study Tools and Data Collection Technique}

1. Personal interview: Based on the available literature ${ }^{15-17}$ a pretested data collection form composed of close-ended and multiple options questions was designed to collect and record the data as follows;

- Socio-demographic characteristics including: Age, gender, residence, occupation, monthly income, and educational status.

- Diabetic history including: Family history of diabetes, family history of DFUs, diabetes management and its duration, and diabetes diagnosis (incidental/screening/symptomatic).

- The lifestyle characteristics: Smoking, alcohol intake, type of foot wear (slippers/sandals/covered shoe), history of exercising, duration, frequency and type of exercise.

2. Examination of patients records: Using a defined data compilation form to assess comorbidities among diabetic patients in relation to the diagnosis of DFUs (cardiac, visual, renal, dyslipidemia, hypertension); the number of comorbid conditions; diabetic complications including PVD, neuropathy, nephropathy, retinopathy, and cardiovascular complications; and the number of diabetic complications.

3. The results of foot examination of the study subjects by a consultant diabetologist and endocrinologist, including presence of healthy skin; foot deformities (callus, hammer / bunion / flatfoot / and claw toe); vibration sense (intact/impaired) over three sites; and also, position sense (intact/impaired).

\section{Pilot Testing}

The preliminary questionnaire used in the personal interview as well as the data compilation form were tested on 28 patients at the outpatient clinics to assess the comprehension, clarity and time required to complete the questionnaire. Accordingly, some questions were modified to be more concise and others were omitted to avoid repetition to end up with the final questionnaire form.

\section{Ethical Considerations}

The study participants received proper orientation about the objectives and expected outcomes of the current study, with emphasis on their right not to participate, and assuring the confidentiality of data. Individual report for each case and control was added to the patient's health record for reference. A written informed consent was obtained from the study subjects. Additionally, the contact number and e-mail address of the principal investigator were provided in case of any inquiries. The study procedures were carried out after approval of the Research Ethics Committee of the "National Institute of Diabetes and Endocrinology" (no. 201901012.05) and according to the ethical requirements of the Declaration of Helsinki.

\section{Statistical Analysis}

Out of 172 cases approached, 159 were included in the final data analysis (13 cases with incomplete health records), while of the 341 invited controls, 329 agreed to participate. Pre-coded data were entered and analyzed using the Statistical Package for Social Sciences (SPSS) software, version 21. Qualitative variables were displayed as numbers and percentages. Quantitative variables were presented as mean \pm standard deviations (SD), and interquartile range (IQR). Univariate analysis was carried out by using Pearson's chi-square test to calculate the crude association between DFUs with the study independent variables. Mann-Whitney test was used for comparing non-parametric quantitative variables, while the Fisherexact test was used for qualitative variables. Significant independent variables (predictors) at the univariate analysis were included in the final multivariate logistic regression model to outline the significant predictors of DFUs (dependent variable) among diabetic patients. The results of logistic regression analysis were presented as Odds Ratio (OR) and 95\% Confidence Interval (CI). P values of $\leq 0.05$ were considered statistically significant. Data will be available upon requesting from the investigators.

\section{Results}

\section{Background Characteristics of the Studied Group in Relation to DFUs}

A total of 488 diabetic patients were recruited for the current study. No significant age difference was found between cases (mean $=54.7+8.6$ years, $\mathrm{IQR}=50-60$ years) and controls (mean $=53.3 \pm 9.8, \quad \mathrm{IQR}=48-60.5$ years). Presence of DFUs was not significantly associated with gender, residence, occupation, and monthly income. A significantly higher percent of cases was illiterate compared to controls $(\mathrm{OR}=1.53,95 \% \mathrm{CI}=1.05-2.24, \mathrm{P}<0.05)$. 
Table I Socio-Demographics and Diabetic History of the Included Patients in Relation to the Diagnosis of Diabetic Foot Ulcer

\begin{tabular}{|c|c|c|c|}
\hline \multirow[t]{2}{*}{ Variables } & \multicolumn{2}{|c|}{ Diabetics: No. (\%) } & \multirow{2}{*}{$\begin{array}{l}\text { Univariate Analysis } \\
\text { Odds Ratio (95\% C.I.) }\end{array}$} \\
\hline & Foot Ulcer $(n=159)$ & None $(n=329)$ & \\
\hline \multicolumn{4}{|l|}{ Age (years): } \\
\hline Mean $\pm S D$ & $54.7 \pm 8.6$ & $53.3 \pm 9.8$ & $0.124^{\dagger}$ \\
\hline Median (IQR) & $55(50-60)$ & $53.0(48-60.5)$ & \\
\hline \multicolumn{4}{|l|}{ Gender: } \\
\hline Males & $83(52.2)$ & $163(49.5)$ & $1.1 \mathrm{I}(0.76-1.62)$ \\
\hline Females & $76(47.8)$ & $166(50.5)$ & Ref. \\
\hline \multicolumn{4}{|l|}{ Residence } \\
\hline Urban & $|4|(88.7)$ & $283(86.0)$ & I.27(0.7I-2.23) \\
\hline Rural & $18(1 \mid .3)$ & $46(14.0)$ & Ref. \\
\hline \multicolumn{4}{|l|}{ Occupational status: } \\
\hline Governmental employees & II(6.9) & $21(6.4)$ & $\mathrm{I} .10(0.5 \mathrm{I}-2.32)$ \\
\hline Self-employed & $59(37.1)$ & $102(31.0)$ & $1.31(0.88-1.95)$ \\
\hline Retired/non-working & $27(17.0)$ & $58(17.6)$ & $0.96(0.58-1.59)$ \\
\hline Housewives & $62(39.0)$ & $148(45.0)$ & Ref. \\
\hline \multicolumn{4}{|l|}{ Monthly income (Egyptian pounds): } \\
\hline$<1000$ & III(69.8) & $228(69.3)$ & $1.02(0.68-1.55)$ \\
\hline $1000-3000$ & $28(17.6)$ & $72(21.9)$ & $0.76(0.47-1.24)$ \\
\hline$>3000$ & $20(12.5)$ & $29(8.8)$ & Ref. \\
\hline \multicolumn{4}{|l|}{ Educational status: } \\
\hline Illiterate/ read and write & $81(50.9)$ & $133(40.4)$ & $1.53(1.05-2.24)^{*}$ \\
\hline Primary/preparatory & $50(31.4)$ & $108(32.8)$ & $0.94(0.62-I .4 I)$ \\
\hline Secondary-technical diploma & $2 I(13.2)$ & $69(20.9)$ & $0.57(0.33-0.97)^{*}$ \\
\hline College or higher & $7(4.4)$ & $19(5.8)$ & Ref. \\
\hline \multicolumn{4}{|l|}{ Marital status: } \\
\hline Married & $140(88.1)$ & $290(88.1)$ & $1.01(0.55-1.78)$ \\
\hline Single & II(6.9) & $22(6.7)$ & $1.04(0.50-2.20)$ \\
\hline Divorced/widowed & $8(5.0)$ & $17(5.2)$ & Ref. \\
\hline Family History of diabetes: & $116(66.7)$ & $229(69.6)$ & $1.04(0.50-2.19)$ \\
\hline Family history of diabetic foot ulcer & $47(29.6)$ & $65(19.8)$ & $1.18(0.77-1.79)$ \\
\hline \multicolumn{4}{|l|}{ Diabetes mellitus diagnosis: } \\
\hline Incidental & $25(15.8)$ & $40(12.2)$ & $\mathrm{I} .10(0.5 \mathrm{I}-2.32)$ \\
\hline Screening & $8(5.0)$ & $36(10.9)$ & $1.35(0.79-2.31)$ \\
\hline Symptomatic & $126(79.2)$ & $253(76.9)$ & Ref. \\
\hline \multicolumn{4}{|l|}{ Diabetes management: } \\
\hline Diet+ OHGs & $21(13.2)$ & $125(38.0)$ & $1.15(0.72-1.82)$ \\
\hline Diet+ OHGs +Insulin & I5(9.4) & $46(14.0)$ & $0.25(0.15-0.41)^{* *}$ \\
\hline Diet + insulin & $123(77.4)$ & $158(48.0)$ & Ref. \\
\hline
\end{tabular}

(Continued) 
Table I (Continued).

\begin{tabular}{|c|c|c|c|}
\hline \multirow[t]{2}{*}{ Variables } & \multicolumn{2}{|c|}{ Diabetics: No. (\%) } & \multirow{2}{*}{$\begin{array}{l}\text { Univariate Analysis } \\
\text { Odds Ratio (95\% C.I.) }\end{array}$} \\
\hline & Foot Ulcer $(n=159)$ & None $(n=329)$ & \\
\hline \multicolumn{4}{|c|}{ Duration of diabetes treatment (years): } \\
\hline $\begin{array}{l}\text { Mean } \pm S D \\
\text { Median (IQR) }\end{array}$ & $\begin{array}{c}14.8 \pm 8.4 \\
15.0(10-20)\end{array}$ & $\begin{array}{c}10.2 \pm 8.1 \\
10.0(6-15)\end{array}$ & $0.00 \mathrm{I}^{\dagger}$ \\
\hline
\end{tabular}

Notes: $* \mathrm{P}<0.05 ; * * \mathrm{P}<0.001$; ${ }^{\dagger}$ Mann Whitney test

Abbreviations: IQR, interquartile range; OHG, oral hypoglycemic drugs; $\mathrm{Cl}$, confidence intervals.

Management of diabetes by diet, oral hypoglycemic drugs (OHGS), and insulin was less significantly associated with DFUs $(9.4 \%$ vs. $14 \%, \mathrm{P}<0.001)$ (Table 1$)$.

\section{Lifestyle Characteristics of the Studied Group in Relation to DFUs}

A significantly higher percentage of cases were current smokers compared to controls, with no significant differences in type (cigarettes, shisha, both) and duration of smoking. As regards type of footwear, wearing covered shoes was less significantly associated with DFUs. Presence of DFUs was not significantly associated with history, duration and frequency of exercising. However, walking was significantly more frequent among cases ( $90.3 \%$ vs. $65.3 \%, \mathrm{P}<0.05)$, while running was more frequent among controls (Table 2).

\section{History of Recorded Comorbid Conditions Among Diabetic Patients in Relation to DFUs}

Although none of the associated recorded comorbidities was significantly associated with DFUs, their number whether two $(\mathrm{P}<0.05)$ or three or more $(\mathrm{P}<0.001)$ was significantly associated with increased risk of DFUs. A significantly higher percent of cases suffered from PVD, peripheral neuropathy, and cardiovascular complications. Presence of two diabetic complications and three or more diabetic complications was significantly more common among cases (Table 3 ).

\section{Results of Foot Examination of the Included Diabetic Patients in Relation to DFUs}

A significantly higher percentage of cases $(\mathrm{P}<0.001)$ suffered from unhealthy skin, and dry/cracked skin. Foot deformities were more significantly present among cases as follows: callus $(46.5 \%$ vs. $14.6 \%, \mathrm{P}<0.001)$, bunion
(20.1\% vs. $10 \%, \mathrm{P}<0.05)$, and flatfoot $(32.7 \%$ vs. $15.2 \%$, $\mathrm{P}<0.001)$. Impaired vibration and position senses were significantly $(\mathrm{P}<0.001)$ associated with DFUs (Table 4).

\section{Predictors of DFUs Among the Included Diabetic Patients}

The multivariate logistic regression model identified the possible predictors for DFUs as follows (Table 5): presence of three or more comorbidities ( $\mathrm{OR}=1.76,95 \%$ $\mathrm{CI}=1.13-2.51 ; \mathrm{P}=0.021$ ), two or more diabetic complications $(\mathrm{OR}=6.053,95 \% \mathrm{CI}=1.742-21.031 ; \mathrm{P}=0.005)$, callus deformity $(\mathrm{OR}=5.200,95 \% \mathrm{CI}=2.318-11.666 ; \mathrm{P}<0.001)$, and flatfoot (OR3.315, 95\% CI=1.509-7.279; $\mathrm{P}=0.003$ ). The significant protective predictors for DFUs in the current study included: management of diabetes by diet, OHGs, and insulin $(\mathrm{OR}=0.528,95 \% \mathrm{CI}=0.342-0.814$; $\mathrm{P}=0.004)$; and intact vibration sense $(\mathrm{OR}=0.294,95 \%$ $\mathrm{CI}=0.132-0.654 ; \mathrm{P}=0.003)$.

\section{Discussion}

Screening to detect risk factors of DFUs is crucial, since most of them are modifiable. ${ }^{15,25}$ Hence, this study was conducted to explore predictors of foot ulcers among Egyptian diabetic patients. Previous studies reported that socio-demographic factors like older age, ${ }^{16,26}$ male gender, ${ }^{15}$ and rural residency ${ }^{17}$ were associated with a higher risk of DFUs. A possible justification is that older age affects wound healing in diabetic patients, ${ }^{27}$ and that women adhere more to life style changes and health-seeking behavior associated with diabetes. ${ }^{28}$ A higher risk of DFUs in rural areas was attributed to illiteracy and poor knowledge about diabetic foot-related complications, and to walking barefooted. ${ }^{6}$ In the current study, none of the aforementioned factors was significantly associated with development of DFUs. Similarly, Al Kafrawy et $\mathrm{al}^{29}$ and Atosona and Larbie ${ }^{30}$ found that age 
Table 2 Lifestyle Characteristics of the Included Patients in Relation to the Diagnosis of Diabetic Foot Ulcer

\begin{tabular}{|c|c|c|c|}
\hline \multirow[t]{2}{*}{ Variables } & \multicolumn{2}{|c|}{ Diabetics: No. (\%) } & \multirow{2}{*}{$\begin{array}{l}\text { Univariate Analysis } \\
\text { Odds Ratio (95\% C.I.) }\end{array}$} \\
\hline & Foot Ulcer $(n=159)$ & None $(n=329)$ & \\
\hline \multicolumn{4}{|l|}{ Smoking } \\
\hline Never & $90(56.6)$ & $203(61.7)$ & $0.8 I(0.55-1.90)$ \\
\hline Current smokers & $58(36.5)$ & $93(28.3)$ & $1.46(1.01-2.18)^{*}$ \\
\hline Ex-smokers & $\mathrm{II}(6.9)$ & $33(10.0)$ & Ref. \\
\hline \multicolumn{4}{|l|}{ Types of smoking (current smokers) } \\
\hline Cigarettes & $29 / 58(50.0)$ & $64 / 93(68.8)$ & $0.93(0.65-0.150)$ \\
\hline Shisha & $14 / 58(24.1)$ & $19 / 93(20.4)$ & $1.57(0.76-3.22)$ \\
\hline Both & $15 / 58(25.9)$ & $10 / 93(10.8)$ & Ref. \\
\hline Duration: current smokers (years): Mean \pm SD & $24.7 \pm 11.7$ & $20.7 \pm 13.5$ & $0.00 \mathrm{I}^{\dagger}$ \\
\hline Duration: ex-smokers (years): Mean \pm SD & $20.1 \pm 13.5$ & $15.3 \pm 10.0$ & $0.001^{\dagger}$ \\
\hline \multicolumn{4}{|l|}{ History of alcohol intake: } \\
\hline Yes & II (6.9) & $20(6.1)$ & $1.15(0.54-2.46)$ \\
\hline No & $148(93.1)$ & $309(93.9)$ & Ref. \\
\hline Duration: alcohol intake (years): Mean ISD & $8.3 \pm 10.5$ & $7.9 \pm 11.7$ & $0.704^{\dagger}$ \\
\hline \multicolumn{4}{|l|}{ Type of footwear: } \\
\hline Slippers & $91(54.1)$ & $172(5 \mid .9)$ & $1.22(0.83-1.79)$ \\
\hline Sandals & $15(10.0)$ & $17(5.2)$ & $1.91(0.93-3.95)$ \\
\hline Covered shoe & $35(22.0)$ & $113(34.3)$ & $0.54(0.34-0.83)^{* *}$ \\
\hline Sandals /covered shoe & $15(9.4)$ & $2 \mathrm{I}(6.4)$ & I.53(0.76-3.05) \\
\hline Slippers/sandals & $7(4.4)$ & $7(2.1)$ & Ref. \\
\hline \multicolumn{4}{|l|}{ History of exercising: } \\
\hline Yes & $62(39.0)$ & 124(37.7) & $1.32(0.90-1.95)$ \\
\hline No & $97(62.0)$ & $205(62.3)$ & Ref. \\
\hline \multicolumn{4}{|l|}{ No. of Exercise/week: } \\
\hline$\leq 3$ times & $36 / 62(58.0)$ & $5 I / I 24(4 I . I)$ & $1.98(1.06-3.67)^{*}$ \\
\hline 4 to 6 times & $22 / 62(35.5)$ & $57 / / 24(46.0)$ & $0.64(0.83-\mid .2 I)$ \\
\hline Daily & $4 / 62(6.5)$ & $16 / 124(12.9)$ & Ref. \\
\hline \multicolumn{4}{|l|}{ Minutes of exercising (minutes/time): } \\
\hline$\leq \mathbf{3 0}$ minutes & $38 / 62(61.3)$ & $75 / 124(60.5)$ & $1.58(0.83-3.02)$ \\
\hline$>30$ minutes & $24 / 62(38.7)$ & $49 / 124(39.5)$ & Ref. \\
\hline \multicolumn{4}{|l|}{ Types of exercise: } \\
\hline Walking & $56 / 62(90.4)$ & $77 / 124(62.1)$ & $5.69(2.27-14.25)^{*}$ \\
\hline Running & $3 / 62(4.8)$ & $27 / \mid 24(2 \mid .8)$ & $0.81(0.05-0.62)^{* \ddagger}$ \\
\hline Football & $2 / 62(3.2)$ & $12 / 124(9.6)$ & Ref. \\
\hline Walking + running & $1 / 62(1.6)$ & $8 / 124(6.5)$ & \\
\hline
\end{tabular}

Notes: ${ }^{*} \mathrm{P}<0.05 ;{ }^{*} * \mathrm{P}<0.00 \mathrm{I} ;{ }^{\dagger}$ Mann Whitney test; ${ }^{\ddagger}$ Fisher exact.

and gender, respectively, are not correlated with DFUs. Variation between studies could be due to different study population and methodology used. Illiteracy was significantly associated with a higher risk of DFUs in the present study, possibly because poor education levels limit the access to information about diabetes and its complications.
Similar findings were reported by Cardoso et al. ${ }^{31}$ In the current study, there was no significant association between the duration of diabetes and DFUs. In contrast, other studies stated that diabetes duration is a risk factor for developing complications especially neuropathy. ${ }^{32,33}$ In this study, treatment modality in the form of diet, OHGs, 
Table 3 History of Recorded Comorbid Conditions Among Diabetic Patients in Relation to the Diagnosis of Diabetic Foot Ulcer

\begin{tabular}{|c|c|c|c|}
\hline \multirow[t]{2}{*}{ Variables } & \multicolumn{2}{|c|}{ Diabetics: No. (\%) } & \multirow{2}{*}{$\begin{array}{l}\text { Univariate Analysis } \\
\text { Odds Ratio ( } 95 \% \text { C.I.) }\end{array}$} \\
\hline & Foot Ulcer $(n=159)$ & None $(n=329)$ & \\
\hline Cardiac (ischemic, failure, previous infarction): & $32(20.1)$ & $65(19.8)$ & $1.02(0.69-1.64)$ \\
\hline Duration (years): mean $\pm \mathrm{SD}$ & $5.6 \pm 5.5$ & $5.2 \pm 9.0$ & 0.0001 \\
\hline Visual (cataract, corneal opacity, etc.): & $60(37.7)$ & $120(36.5)$ & $1.06(0.7 I-1.56)$ \\
\hline Duration (years): mean $\pm \mathrm{SD}$ & $5.1 \pm 5.2$ & $4.7 \pm 5.5$ & 0.435 \\
\hline Renal (stones, nephritis, urinary infections): & $16(10.1)$ & $39(11.8)$ & $0.83(0.45-1.54)$ \\
\hline Duration (years): mean $\pm \mathrm{SD}$ & $5.9 \pm 5.2$ & $4.4 \pm 3.0$ & 0.008 \\
\hline Dyslipidemia (received treatment): & $4 I(25.8)$ & $97(29.5)$ & $0.83(0.54-1.27)$ \\
\hline Duration (years): mean $\pm S D$ & $3.3 \pm 2.1$ & $5.7 \pm 4.9$ & 0.001 \\
\hline Hypertension (diagnosed/receiving treatment): & $70(44.0)$ & $161(48.9)$ & $0.84(0.57-1.23)$ \\
\hline Duration (years): mean $\pm \mathrm{SD}$ & $11.3 \pm 8.1$ & $8.1 \pm 6.3$ & 0.001 \\
\hline Comorbid others!: & II (6.9) & $16(4.9)$ & $1.45(0.66-3.21)$ \\
\hline \multicolumn{4}{|l|}{ Number of morbid conditions: } \\
\hline Two co-morbidities & $38(23.9)$ & $53(16.1)$ & $1.64(1.02-2.61)^{*}$ \\
\hline Three or more co-morbidities & $121(76.1)$ & $201(61.1)$ & $1.88(1.22-2.89)^{* *}$ \\
\hline \multicolumn{4}{|l|}{ Diabetes complications: } \\
\hline Peripheral vascular disease & $13(8.1)$ & $4(1.2)$ & $7.20(2.40-26.02)^{*}$ \\
\hline Retinal problems & $6(3.8)$ & $7(2.1)$ & $1.80(0.49-6.37) \ddagger$ \\
\hline Peripheral neuropathy & $46(28.9)$ & $61(20.9)$ & $1.78(1.14-2.78)^{* *}$ \\
\hline Cardiovascular complications & $57(35.8)$ & $89(27.1)$ & $1.51(1.01-2.26)^{*}$ \\
\hline Renal disease (nephropathy) & $5(3.1)$ & $3(0.9)$ & $3.52(0.67-22.94)^{\ddagger}$ \\
\hline \multicolumn{4}{|l|}{ Multiplicity of diabetes complications: } \\
\hline One & $5(3.1)$ & $15(4.6)$ & Ref. \\
\hline Two & $99(62.2)$ & $155(47.1)$ & $1.85(1.26-2.72)^{* *}$ \\
\hline Three or more & $20(12.6)$ & $19(5.8)$ & $2.34(1.21-4.53)^{*}$ \\
\hline
\end{tabular}

Notes: !ncludes: anemia, thyroid disease, gout, arthritis, hemolytic blood diseases, hepatitis C, fatty liver and liver cirrhosis; ${ }^{* P}<0.05$; ${ }^{* * P}<0.00 \mathrm{I} ;{ }^{\ddagger}$ Fisher Exact.

and insulin was a protective predictor of DFUs. A possible explanation is that insulin was added to OHGs for a better control of blood glucose levels and to prevent complications like diabetic foot. ${ }^{34}$ In contrast, Atosona and Larbie (2019) reported that diet, insulin, and OHGs are not correlated with DFUs. ${ }^{30}$ Moreover, Al-Rubeaan el $\mathrm{al}^{32}$ and Banik et $\mathrm{al}^{6}$ stated that insulin was associated with a significant risk of foot ulcers and amputations, and justified that insulin use was probably a result not a cause of uncontrolled blood glucose and occurrence of complications. ${ }^{15}$

Smoking is a major risk factor of PVD, one of the main causes of DFUs. ${ }^{35}$ In the current study, smoking was significantly associated with DFUs, which was also supported by many studies. ${ }^{29,36}$ In contrast, Coppini et al did not find any association between smoking and foot complications which may be due to biologic plausibility. ${ }^{37}$ Previous research postulated that alcohol intake is linked with nerve damage which may predispose to foot ulcers and amputations; ${ }^{30}$ however, no correlation was found between alcohol intake and DFUs in the present study and others as well. ${ }^{38,39}$

In the current study, wearing covered shoes was significantly less associated with DFUs $(\mathrm{P}<0.001)$, which suggests a protective effect of appropriate foot wear in diabetic patients as recommended by the IWGDF guidelines. ${ }^{14}$ Similarly, Sriyani et al stated that wearing slippers as opposed to sandals and covered shoes increases the risk of foot ulcers by 3-4 folds. ${ }^{40}$ About $38 \%$ only of the included participants in this study were practicing physical exercise; running was significantly more frequent among controls which could be explained by the fact that foot ulcers limited the physical activity of cases.

The role of dyslipidemia in the etiology of PVD, one of the major risk factors of DFUs, is inconsistent. ${ }^{41}$ Hence, the current study like others did not find a significant association between dyslipidemia and DFUs. ${ }^{30,42}$ Diabetic patients with severe PVD have a higher tendency 
Table 4 Results of Foot Examination of the Included Diabetic Patients in Relation to the Presence of Diagnosed Foot Ulcer

\begin{tabular}{|c|c|c|c|}
\hline \multirow[t]{2}{*}{ Variables } & \multicolumn{2}{|c|}{ Diabetics: No. (\%) } & \multirow{2}{*}{$\begin{array}{l}\text { Univariate Analysis } \\
\text { Odds Ratio (95\% C.I.) }\end{array}$} \\
\hline & Foot Ulcer $(n=159)$ & None $(n=329)$ & \\
\hline Healthy skin: No & $78(49.1)$ & $60(18.2)$ & $4.32(2.84-6.56)^{* *}$ \\
\hline Dry/cracked skin & $95(59.7)$ & $125(38.0)$ & $2.42(1.65-3.57)^{* *}$ \\
\hline Discolored skin & $75(47.2)$ & $272(82.7)$ & $4.26(2.79-6.50)^{* *}$ \\
\hline \multicolumn{4}{|l|}{ Foot deformities: } \\
\hline Callus & $74(46.5)$ & $48(14.6)$ & $5.10(3.29-7.88)^{* *}$ \\
\hline Hammer /claw toe & $47(29.6)$ & $7 I(2 I .6)$ & $1.52(1.00-2.34)$ \\
\hline Bunion & $32(20.1)$ & $33(10.0)$ & $2.26(1.33-3.83)^{*}$ \\
\hline Flatfoot & $52(32.7)$ & $50(15.2)$ & $2.7 I(1.73-4.24)^{* *}$ \\
\hline Claw toe & $6(3.8)$ & $4(1.2)$ & $3.19(0.88-11.46)$ \\
\hline Two or more deformities & $27(16.9)$ & $5 I(15.5)$ & I.II(0.67-I.86) \\
\hline \multicolumn{4}{|l|}{ Vibration sense: } \\
\hline Intact & $29(18.2)$ & 197(59.9) & Ref. \\
\hline Impaired & $130(81.8)$ & $132(40.1)$ & $6.69(4.23-10.59)^{* *}$ \\
\hline Site: & & & \\
\hline One & $26 / 130(20)$ & $37 / 132(28)$ & Ref. \\
\hline Two & $50 / 130(38.5)$ & $63 / 132(47.7)$ & $0.68(0.42-1.12)$ \\
\hline Three sites & $54 / \mid 30(4 \mid .5)$ & $32 / 132(24.3)$ & $2.22(1.31-3.77)^{* *}$ \\
\hline \multicolumn{4}{|l|}{ Position sense: } \\
\hline Intact & $48(30.2)$ & $234(7 I .1)$ & Ref. \\
\hline Impaired & III(69.8) & $95(28.9)$ & $5.69(3.76-8.62)^{* *}$ \\
\hline \multicolumn{4}{|l|}{ Sites: } \\
\hline One & $|2 /|||(\mid 0.8)$ & $13 / 95(13.7)$ & Ref. \\
\hline Two & $48 / I I I(43.2)$ & $37 / 95(38.9)$ & $1.19(0.68-2.10)$ \\
\hline Three sites & $5 \mathrm{I} / \mathrm{III}(46)$ & $45 / 95(47.4)$ & $1.02(0.68-1.76)$ \\
\hline
\end{tabular}

Notes: $* \mathrm{P}<0.05 ; * * \mathrm{P}<0.001$.

Table 5 Multivariate Logistic Regression Model of the Possible Predictors for Diabetic Foot Ulcer Among the Included Sample

\begin{tabular}{|l|c|c|c|c|c|}
\hline Independent Variables & B & Odds Ratio & \multicolumn{2}{|c|}{$95 \%$ Confidence Intervals } \\
\cline { 3 - 6 } & & & Lower & Upper \\
\hline Education (less than secondary) & 0.163 & 1.177 & 0.496 & 2.793 & 0.712 \\
Smoking (current) & -0.597 & 0.550 & 0.263 & 1.153 & 0.114 \\
Footwear (covered) & -0.225 & 0.799 & 0.385 & 1.657 & 0.546 \\
Three or more co-morbidities & 0.864 & 1.76 & 1.13 & 2.51 & 0.021 \\
Management (diet+OHGs +insulin) & -0.638 & 0.528 & 0.342 & 0.814 & 0.004 \\
Duration of diabetes & -0.004 & 0.996 & 0.953 & 1.040 & 0.841 \\
Diabetes Complications (two or more) & 1.801 & 6.053 & 1.742 & 21.031 & 0.005 \\
Cracked skin & 0.313 & 1.367 & 0.632 & 2.959 & 0.427 \\
Callus & 1.649 & 5.200 & 2.318 & 1.666 & 0.000 \\
Hammertoe & 0.516 & 1.674 & 0.806 & 3.477 & 0.167 \\
Flatfoot & 1.198 & 3.315 & 1.509 & 7.279 & 0.003 \\
Vibration sense (intact, 3 sites) & -1.226 & 0.294 & 0.132 & 0.654 & 0.003 \\
Position sense (intact) & -0.783 & 0.457 & 0.134 & 1.558 & 0.211 \\
\hline
\end{tabular}

Notes: Model \% predicted=82.8\%; Hosmer-Lemeshow Chi-square=17.21 I; $P=0.028 ;$ Nagelkerke $\mathrm{R}^{2}=0.513$. 
of developing sudden ischemia due to arterial thrombosis, which in turn increases the risk of foot ulcers and amputations. $^{29}$ In the current study, PVD was a significant risk factor of DFUs, which was supported by another studies conducted in Egypt, ${ }^{29}$ Canada, $^{43}$ and Italy. ${ }^{44}$ Diabetic patients with neuropathy are also more liable to foot ulceration due to high pressure load and shearing forces. ${ }^{29}$ Having peripheral neuropathy was significantly associated with DFUs in the present study, which was consistent with other studies done in Ethiopia, ${ }^{17}$ Egypt, $^{45}$ and Jordan. ${ }^{46}$

Previous research indicated that foot deformities increase the risk of occurrence of foot ulcers directly by ulcer development and indirectly by increased plantar pressure. ${ }^{43}$ In the present study, there was a significant association between foot deformities including callus, bunion, and flatfoot and DFUs. Similar findings were concluded by Al Kafrawy et $\mathrm{al}^{29}$ and Yazdanpanah et al. ${ }^{15}$

Sensory peripheral neuropathy, one of the common complications of DM is associated with impairments of vibration sense and joint position sense. Impaired vibration sense is a risk factor of DFUs, ${ }^{47}$ while impaired position sense increases the incidence of falls, soft tissue injuries and fractures. ${ }^{48}$ In the current study, impaired vibration and position senses were significant risk factors of DFUs in the univariate analysis, while only intact vibration sense was a significant protective predictor in the multivariate logistic regression analysis. Similar findings were reported by Sriyani et al (2013) where there was a significant association between impairment of all three sensations (vibration, pressure, and position) and DFUs in the univariate analysis, however; only impairment of vibration and pressure senses were significant in the final logistic regression model. ${ }^{40}$

In the current study, significant positive predictors of DFUs on multivariate logistic regression analysis were presence of three or more comorbidities, two or more diabetic complications, callus and flatfoot. In a study conducted by Yazdanpanah et al, risk factors of DFUs on multivariate analysis were diabetes duration, educational level, marital status, smoking, glycemic control, retinopathy, nephropathy, and decreased peripheral pulses. ${ }^{15}$

Despite the current study provides valuable information for health care providers to implement preventive measures for DFUs, it has some limitations as follows; it adopted a casecontrol study design which does allow for establishing a cause-effect relationship. Moreover, it did not take into account some potential confounders like level of health services' provision and patients' compliance with foot care practices.

\section{Conclusion and Recommendations}

Significant positive predictors of DFUs on multivariate analysis were; presence of three or more comorbidities, two or more diabetic complications, callus and flatfoot, while protective predictors were management of diabetes by diet, OHGs, and insulin; and intact vibration sense. Hence, special care should be provided to diabetic patients with comorbidities and complications to reduce the risk of DFUs. In addition, health education should be provided to diabetic patients regarding risk factors of DFUs and foot care practices. The role of health care systems and policy makers should not be restricted to treatment of DFUs, but should also extend to taking effective measures for prevention.

\section{Acknowledgments}

The authors are thankful to all the physicians who helped in the data collection process. We would also like to thank all patients who participated in this study.

\section{Disclosure}

The authors report no conflicts of interest in this work. This research did not receive grant from any funding agency in the public, commercial, or not-for-profit sectors.

\section{References}

1. Tabish SA. Is diabetes becoming the biggest epidemic of the twenty-first century? Int J Health Sci. 2007;1(2):V-VIII.

2. International Diabetes Federation. IDF Diabetes Atlas. 9th. IDF; 2019. Available from: https://www.diabetesatlas.org/upload/resources/mate rial/20200302_133351_IDFATLAS9e-final-web.pdf. Accessed December 25, 2019.

3. Ogurtsova K, da Rocha Fernandes JD, Huang Y, et al. IDF Diabetes Atlas: global estimates for the prevalence of diabetes for 2015 and 2040. Diabetes Res Clin Pract. 2017;128:40-50. doi:10.1016/j. diabres.2017.03.024

4. Hegazi R, El-Gamal M, Abdel-Hady N, Hamdy O. Epidemiology of and risk factors for type 2 diabetes in Egypt. Ann Glob Heal. 2015;81 (6):814-820. doi:10.1016/j.aogh.2015.12.011

5. Jain AKC. A new classification of diabetic foot complications: a simple and effective teaching tool. J Diabet Foot Complicat. 2012;4(1):1-5.

6. Banik PC, Barua L, Moniruzzaman M, Mondal R, Zaman F, Ali L. Risk of diabetic foot ulcer and its associated factors among Bangladeshi subjects: a multicentric cross-sectional study. $B M J$ Open. 2020;10(2):1-10. doi:10.1136/bmjopen-2019-034058

7. Eleftheriadou I, Kokkinos A, Liatis S, et al. Atlas of the Diabetic Foot. 3rd ed. Malden, MA: Wiley-Blackwell; 2019.

8. Adem AM, Andargie AA, Teshale AB, Wolde HF. Incidence of diabetic foot ulcer and its predictors among diabetes mellitus patients at Felege Hiwot Referral Hospital, Bahir Dar, Northwest Ethiopia: a retrospective follow-up study. Diabetes Metab Syndr Obes. 2020;13:3703-3711. doi:10.2147/DMSO.S280152 
9. Jeyaraman K, Berhane T, Hamilton M, Chandra AP, Falhammar H. Mortality in patients with diabetic foot ulcer: a retrospective study of 513 cases from a single Centre in the Northern Territory of Australia. BMC Endocr Disord. 2019;19(1):1. doi:10.1186/s12902018-0327-2

10. Kumhar M, Dara N, Saini T. Foot wear and footcare knowledge- an independent risk factor for diabetic foot in Indian diabetics. Ind Med Gaz. 2014;148(1):25-28.

11. Zhang P, Lu J, Jing Y, Tang S, Zhu D, Bi Y. Global epidemiology of diabetic foot ulceration: a systematic review and meta-analysis. Ann Med. 2017;49(2):106-116. doi:10.1080/07853890.2016.1231932

12. Assaad-Khalil SH, Zaki A, Rehim AA, et al. Prevalence of diabetic foot disorders and related risk factors among Egyptian subjects with diabetes. Prim Care Diabetes. 2015;9(4):297-303. doi:10.1016/j. pcd.2014.10.010

13. Al-Ghazaly G, Al-Ahwal L, Zagloul K. Risk factors of diabetic foot ulcer in patients attending diabetic foot outpatient clinic at Tanta University Hospital in Egypt. J Diabet Foot Complicat. 2015;7 (2):42-48.

14. Scheper N, Van Netten JJ, Apelqvist J, Bus SA, Hinchliffe RJ, Lipsky BA. International working group on the diabetic foot guidelines in the prevention and management of diabetic foot disease; 2019. Available from: https://iwgdfguidelines.org/wp-content /uploads/2019/05/IWGDF-Guidelines-2019.pdf. Accessed August 10, 2021.

15. Yazdanpanah L, Shahbazian H, Nazari I, et al. Incidence and risk factors of diabetic foot ulcer: a population-based diabetic foot cohort (ADFC study)-two-year follow-up study. Int $J$ Endocrinol. 2018;2018. doi:10.1155/2018/7631659

16. Fawzy MS, Alshammari MA, Alruwaili AA, et al. Factors associated with diabetic foot among type 2 diabetes in Northern area of Saudi Arabia: a descriptive study. BMC Res Notes. 2019;12(1):51. doi:10.1186/s13104-019-4088-4

17. Mariam TG, Alemayehu A, Tesfaye E, et al. Prevalence of diabetic foot ulcer and associated factors among adult diabetic patients who attend the diabetic follow-up clinic at the university of Gondar Referral Hospital, North West Ethiopia, 2016: institutional-based cross-sectional study. J Diabetes Res. 2017;2017. doi:10.1155/2017/2879249

18. Deribe B, Woldemichael K, Nemera G. Prevalence and factors influencing diabetic foot ulcer among diabetic patients attending Arbaminch Hospital, South Ethiopia. J Diabetes Metab. 2014;5 (1):1-7. doi:10.4172/2155-6156.1000322

19. Naemi R, Chockalingam N, Lutale JK, Abbas ZG. Can a combination of lifestyle and clinical characteristics explain the presence of foot ulcer in patients with diabetes? J Diabetes Complications. 2019;33 (6):437-444. doi:10.1016/j.jdiacomp.2019.02.006

20. World Health Organization. Definition and diagnosis of diabetes mellitus and intermediate hyperglycemia. Report of a WHO/IDF consultation. Geneva, Switzerland: WHO; 2006. Available from: https://www.who.int/diabetes/publications/Definition\%20and $\%$ 20diagnosis\%20of\%20diabetes_new.pdf. Accessed December 22, 2019.

21. Apelqvist J, Bakker K, van Houtum WH, Nabuurs-Franssen MH, Schaper NC. International working group on the diabetic foot. Maastricht, Netherlands; 1999.

22. Open Epi. Open source epidemiologic statistics for public health; 2013. Available from: https://www.openepi.com/Menu/OE_Menu. htm. Accessed January 9, 2019.

23. Kogani M, Mansournia M, Doosti-Irani A, Holakouie-Naieni K. Risk factors for amputation in patients with diabetic foot ulcer in southwest Iran: a matched case-control study. Epidemiol Health. 2015;37: e2015044. doi:10.4178/epih/e2015044

24. Bañuelos-Barrera P, Arias-Merino ED, Bañuelos-Barrera Y. Risk factors of foot ulceration in patients with diabetes mellitus type 2 . Invest Educ Enferm. 2013;31(3):442-449.
25. Salameh BS, Abdallah J, Naerat EO. Case-control study of risk factors and self-care behaviors of foot ulceration in diabetic patients attending primary healthcare services in palestine. $J$ Diabetes Res. 2020;2020. doi:10.1155/2020/7624267

26. Sarinnapakorn V, Sunthorntepwarakul T, Deerochanawong C, Niramitmahapanya S, Napartivaumnuay N. Prevalence of diabetic foot ulcers and risk classifications in type 2 diabetes mellitus patients at Rajavithi Hospital. J Med Assoc Thai. 2016;99(2):S99-S105.

27. Guo S, DiPietro LA. Factors affecting wound healing. J Dent Res. 2010;89(3):219-229. doi:10.1177/0022034509359125

28. Rossaneis MA, MdoCFL H, TAdeF M, Marcon SS. Differences in foot self-care and lifestyle between men and women with diabetes mellitus. Rev Lat Am Enfermagem. 2016;24:e2761. doi:10.1590/ 1518-8345.1203.2761

29. Al Kafrawy NA, Mustafa EA, Abd El-Salam AE, et al. Study of risk factors of diabetic foot ulcers. Menoufia Med J. 2014;27(1):28-34. doi:10.4103/1110-2098.132298

30. Atosona A, Larbie C. Prevalence and determinants of diabetic foot ulcers and lower extremity amputations in three selected tertiary hospitals in Ghana. $J$ Diabetes Res. 2019;2019:7132861. doi:10.1155/2019/7132861

31. Cardoso HC, Zara AL, SdS R, et al. Risk factors and diagnosis of diabetic foot ulceration in users of the Brazilian Public Health System. J Diabetes Res. 2019;2019:5319892. doi:10.1155/2019/5319892

32. Al-Rubeaan K, Al Derwish M, Ouizi S, et al. Diabetic foot complications and their risk factors from a large retrospective cohort study. PLoS One. 2015;10(5):e0124446. doi:10.1371/journal.pone.0124446

33. Hajieh S, Leila Y, Seyyed L. Risk assessment of patients with diabetes for foot ulcers according to risk classification consensus of international working group on diabetic foot (IWGDF). Pak J Med Sci. 2013;29(3):730-734.

34. Ndip A, Rutter MK, Vileikyte L, et al. Dialysis treatment is an independent risk factor for foot ulceration in patients with diabetes and stage 4 or 5 chronic kidney disease. Diabetes Care. 2010;33 (8):1811-1816. doi:10.2337/dc10-0255

35. Levin ME. Pathogenesis and general management of foot lesions in the diabetic patient. In: Bowker JH, Pfeifer MA, editors. The Diabetic Foot. 6th ed. St Louis: Mosby; 2011:219-260.

36. Hassan M, Mohamed A. Associated risk factors and management of chronic diabetic foot ulcers exceeding 6 months' duration. Diabet Foot Ankle. 2012;3:10.

37. Coppini DV, Young PJ, Weng C. Outcome on diabetic foot complications in relation to clinical examination and quantitative sensory testing: a case- control study. Diabet Med. 1998;15:765-771. doi:10.1002/ (SICI)1096-9136(199809)15:9<765::AID-DIA663>3.0.CO;2-1

38. Achiwanga FS, Njelekela MA. Diabetic foot: prevalence and risk factors, knowledge and practices of foot care among diabetic patients attending public diabetic clinics in Dar-Es-Salaam, Tanzania. $J$ Foot Ankle Res. 2015;8(20):1-7.

39. Adam ES, Mahmoud SM, Ahmed E. Tobacco and alcohol use as risk factors for major lower extremity amputation in diabetics. Khartoum Med J. 2009;2(1):172-174.

40. Sriyani KA, Wasalathanthri S, Hettiarachchi P, Prathapan S. Predictors of diabetic foot and leg ulcers in a developing country with a rapid increase in the prevalence of diabetes mellitus. PLoS One. 2013;8(11):e80856. doi:10.1371/journal.pone.0080856

41. Premalatha G, Shanthirani S, Deepa R, Markovitz J, Mohan V. Prevalence and risk factors of peripheral vascular disease in a selected south Indian population: the Chennai Urban Population Study. Diabetes Care. 2000;23(9):1295-1300. doi:10.2337/ diacare.23.9.1295

42. Hellar AM, Mbembati NAA. The pattern and surgical management of diabetic foot at Muhimbili National Hospital, Dar-es-salaam, Tanzania. East Cent Afr J Surg. 2011;16(1). Available from: https://www.ajol.info/index.php/ecajs/article/view/72484. Accessed September 8, 2021. 
43. Reid KS, Martin BD, Duerksen F, et al. Diabetic foot complications in a northern Canadian Aboriginal Community. Foot Ankle Int 2006;27:1065-1073. doi:10.1177/107110070602701212

44. Formosa C, Gatt A, Chockalingam N. Diabetic foot complications in Malta: prevalence of risk factors. Foot. 2012;22:294-297. doi:10.1016/j.foot.2012.08.008

45. Saad N, Elhadedy K, Ramadan N, Mohmady O, Farid M. The prevalence and risk categorization of diabetic foot complications in cohort group in, Beni Suif, Egypt. Life Sci J. 2013;3:10.
46. Bakri FG, Allan AH, Khader YS, Younes NA, Ajlouni KM. Prevalence of diabetic foot ulcer and its associated risk factors among diabetic patients. Jordan Med J. 2011;46(2):118-125.

47. Ennion L, Hijmans J. Improving vibration perception in a patient with type 2 diabetes and sensory peripheral neuropathy. $S A f r$ J Physiother. 2019;75(1):a602. doi:10.4102/sajp.v75i1.602

48. Guney H, Kaya D, Citaker S, et al. Is there any loss of ankle proprioception in diabetic patients without neuropathy? Isokinet Exerc Sci. 2013;21(4):317-323. doi:10.3233/IES-130503

\section{Publish your work in this journal}

Risk Management and Healthcare Policy is an international, peerreviewed, open access journal focusing on all aspects of public health, policy, and preventative measures to promote good health and improve morbidity and mortality in the population. The journal welcomes submitted papers covering original research, basic science, clinical \& epidemiological studies, reviews and evaluations, guidelines, expert opinion and commentary, case reports and extended reports. The manuscript management system is completely online and includes a very quick and fair peer-review system, which is all easy to use. Visit http://www.dovepress.com/testimonials.php to read real quotes from published authors.

Submit your manuscript here: https://www.dovepress.com/risk-management-and-healthcare-policy-journal 